\title{
PHYSICAL ACTIVITY ASSESSMENT USING A MODIFIED PAQ-C QUESTIONNAIRE
}

\author{
Stefan Kolimechkov, Lubomir Petrov, Albena Alexandrova \\ National Sports Academy 'Vassil Levski', Bulgaria
}

\begin{abstract}
Summary
Physical activity plays an important role in a child's development and is a powerful indicator of their health and well-being, and its assessment is an essential part of monitoring and surveillance in schools. The aim of this study was to measure and assess general levels of physical activity amongst Bulgarian and English children by applying a selfreported questionnaire. In total, 94 participants between the ages of 7 and 10, divided into four groups depending on their nationality and gender, took part in this study. Physical activity was measured by using the PAQ-C questionnaire, which was modified and adjusted for the purposes of our study. Weight, height and waist circumference were measured, and BMI and Waist-to-Height ratio were calculated. The Z-scores and percentile scores for weight, height and BMI were calculated and assessed using WHO software. The data was analysed by using one-way ANOVA with Bonferroni post hoc test. The final scores of the modified PAQ-C questionnaire for all four groups were recorded and shown to be within the range of medium physical activity for children (PAQ-C score $>2.50$ and $<3.50$ ), but there were significant

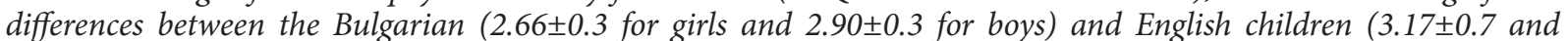
$3.41 \pm 0.6$, respectively), $(p<0.05)$. There was no significant difference between overweight and obese children (BMI $Z$-score $>+1 S D$ ) and children with BMI within the norm (BMI Z-score <+1SD and >-1SD) in terms of the PAQ-C score, which has also been observed by other authors. Further research needs to be carried out on the Bulgarian population in order to obtain normative PAQ scores for children and adolescents.
\end{abstract}

Key Words: children, obese, overweight, waist-to-height ratio

\section{Introduction}

Physical activity (PA) includes any body movement produced by the contractions of skeletal muscles that increase energy expenditure (American_College_of_Sports_Medicine, 2014), plays an important role in children's development, and it is a powerful indicator of their health and well-being. The benefits of PA are well-documented and include: improved health of muscles, bones, and joints, positive social and mental health, and a decreased chance of developing diseases (U.S._Department of_Health_and_Human_Services, 1996, Elliot et al., 2013). Based on these benefits, the World Health Organisation and the American Society of Health and Physical Educators recommend that children and adolescents should spend a minimum of one hour per day in moderate to vigorously intense PA (WHO, 2010, Ganley et al., 2011, Elliot et al., 2013).

The assessment of PA is an essential part of profiling and monitoring in schools. Subjective methods for assessing physical activity, such as questionnaires, interviews and diaries, are often preferred to the objective ones (heart rate monitors, pedometer, and accelerometer) because of the simplicity with which they are conducted on children, without the need for special equipment (Bervoets et al., 2014). However, self-reporting questionnaires have their own difficulties due to the nature of the children's activity patterns and their lack of cognitive ability to accurately recall the amount and intensity of activity (Hagstromer and Sjostrom, 2010).

A systematic review, which was carried out on many available self-report questionnaires for assessing PA in children and adolescents, identified three such questionnaires as potentially most suitable: Youth Risk Behaviour Surveillance Survey (YRBS), Teen Health Survey, and The Physical Activity Questionnaire (PAQ-C/PAQ-A) (Biddle et al., 2011).

The Youth Risk Behaviour Surveillance Survey (YRBS) was developed in 1989 by the Center for Disease Control and Prevention (CDC) to monitor health risk behaviours that contribute to the leading causes of mortality, morbidity, and social problems amongst adolescents and adults in the United States (Brener et al., 1995). The Teen Health Survey was developed for adolescents only, and includes just two items (Biddle et al., 2011).

The Physical Activity Questionnaire (PAQ-C/ PAQ-A) has two slightly different versions, one for elementary school children (8-14 years of age) and one for high school students (14-20 years of age). The questionnaires use a common scoring system and were applied successfully in many studies (Kowalski et al., 2004). Results indicated that PAQ-C pro- 
vides a reliable and valid measure of general physical activity levels in children during the school year (Crocker et al., 1997, Kowalski et al., 1997, Wang et al., 2016). PAQ-C is based on questions for the last seven days and requires participants to check a list of activities, as far as frequency is concerned, by using the following scale: 'None,' ' $1-2$ times per week', '3-4 times', '5-6 times', ' 7 times or more.' The other questions cover 'physical activity in PE lessons', 'recess', 'lunch time, 'right after school', and 'evenings', as well as 'the last weekend'. A five-scale measure of frequency of participation is given for each question. The Physical Activity Questionnaire for Older Children (PAQ-C) has been used to classify children and adolescents into different activity levels and to investigate the relationship between physical activity and health outcomes (Kowalski et al., 2004).

\section{Aim and Objectives of the study}

The aim of this study was to measure and assess the general level of physical activity amongst Bulgarian and English school children by applying a modified PAQ-C questionnaire.

\section{Methods}

In total, 94 participants ( 30 females and 31 males from Bulgaria, and 15 females and 18 males from England) between the ages of 7 and 10 took part in this study. Informed consent was obtained from the parent/guardian of each child.

The anthropometric parameters, weight, height and waist circumference, were measured, and the BMI was calculated as: weight in kilograms / height in metres squared. Body weight was measured to within an accuracy of $0.1 \mathrm{~kg}$ by using an electronic scale, and height was measured to the nearest $0.1 \mathrm{~cm}$ with a stadiometer. The Z-scores and percentile scores for weight, height and BMI of each individual were calculated and assessed by using specialised software of the World Health Organisation, called 'WHO Anthro Plus' (WHO, 2007). Waist circumference was measured to the nearest 0.1 $\mathrm{cm}$ with the Lufkin W606PM anthropometric tape measure, and Waist-to-Height ratio was calculated as: waist circumference $(\mathrm{cm}) /$ height $(\mathrm{cm})$.

In order to measure and assess levels of physical activity, we applied a widely used questionnaire for children, called PAQ-C (Kowalski et al., 2004), after adjusting it for our purposes (STK-SPORT, 2017a). Firstly, questions were reformulated to obtain in- formation about a "usual week" (instead of the last seven days). Secondly, Question 9 (Q9 - physical activity frequencies for each day from the last week), and Q10 (Were you sick last week?) were excluded from the original PAQ-C test, as these questions did not fit into the modified test, which is concerned with a "usual week". Instead of Q9 and Q10, we added two new questions for verification of Q2 (activity during physical education classes) and Q3 (break-time activity), in which we asked the same thing in a different way in order to exclude children who answer such questions without paying attention. The scoring system of the test remained the same as in the original PAQ-C, where a value of 1 indicates low physical activity and a value of 5 indicates high physical activity for each question. The final PAQ-C activity score of the test is calculated as the mean value of the answers to the first eight questions. In addition, a Bulgarian language version of the test was provided (STK-SPORT, 2017b).

One-way ANOVA with Bonferroni post hoc test was applied to analyse the data from all participants, divided into four groups depending on their nationality and gender. In addition, eta-squared measure of effect size for use in ANOVA $\left(\eta^{2}\right)$ (Lakens, 2013) was also calculated in order to present the magnitude of the effects. Statistically significant differences between the average values were evaluated at $p<0.05$, and all data in the text are presented as average \pm SD.

\section{Results}

After calculating the differences between Q2, Q3 and their verification questions, we discovered that thirteen children (three Bulgarian females, seven English females, and three English males) did not provide reliable enough answers according to the criteria which we set (the sum of the differences was greater than a value of 2), and therefore they were excluded from the study. Following this test verification, the groups were reduced to 27 females and 31 males from Bulgaria, and 8 females and 15 males from England.

The anthropometric data of the participants is presented in Table 1. Their age, weight, height and their Z-scores and percentile scores, as well as BMI, BMI Z-score, waist circumference and waist-toheight ratio did not show any significant statistical differences between the groups. Only in the BMI percentile score was there a significant difference between English girls and boys $(\mathrm{p}<0.05)$. 
Table 1. Anthropometric data of all 81 participants who passed the test verification criteria (Mean \pm SD)

\begin{tabular}{|l|c|c|c|c|}
\hline & $\begin{array}{c}\text { Bulgarian Females } \\
(\mathrm{n}=27)\end{array}$ & $\begin{array}{c}\text { Bulgarian Males } \\
(\mathrm{n}=31)\end{array}$ & $\begin{array}{c}\text { EnglishFemales } \\
(\mathrm{n}=8)\end{array}$ & $\begin{array}{c}\text { English Males } \\
(\mathrm{n}=15)\end{array}$ \\
\hline Age $(\mathrm{y})$ & $9.0 \pm 0.6$ & $8.8 \pm 0.5$ & $8.7 \pm 0.4$ & $8.6 \pm 0.4$ \\
\hline Weight $(\mathrm{kg})$ & $34.1 \pm 8.0$ & $33.0 \pm 6.7$ & $35.8 \pm 13.1$ & $34.6 \pm 5.8$ \\
\hline Weight Z-score & $0.9 \pm 1.1$ & $0.9 \pm 1.3$ & $1.2 \pm 1.5$ & $1.4 \pm 0.9$ \\
\hline Weight Perc. Score & $71.3 \pm 24.5$ & $72.1 \pm 27.5$ & $69.6 \pm 25.8$ & $86.1 \pm 13.7$ \\
\hline Height (cm) & $137.0 \pm 7.2$ & $136.0 \pm 7.7$ & $136.8 \pm 8.3$ & $134.4 \pm 4.6$ \\
\hline Height Z-score & $0.7 \pm 0.94$ & $0.7 \pm 1.2$ & $0.9 \pm 1.3$ & $0.7 \pm 0.7$ \\
\hline Height Perc. Score & $68.9 \pm 25.8$ & $68.0 \pm 29.9$ & $66.4 \pm 25.9$ & $71.4 \pm 20.0$ \\
\hline BMI (kg/m2) & $18.0 \pm 3.1$ & $17.7 \pm 2.3$ & $19.0 \pm 5.4$ & $19.1 \pm 2.6$ \\
\hline BMI Z-score & $0.7 \pm 1.1$ & $0.8 \pm 1.1$ & $0.8 \pm 1.8$ & $1.4 \pm 1.0$ \\
\hline BMI Perc. Score & $65.2 \pm 26.7$ & $69.0 \pm 27.9$ & $50.2 \pm 30.1^{*}$ & $84.7 \pm 15.6^{*}$ \\
\hline Waist circ. (cm) & $64.8 \pm 6.2$ & $64.3 \pm 6.6$ & $63.6 \pm 10.6$ & $64.8 \pm 6.3$ \\
\hline WHtR & $0.47 \pm 0.1$ & $0.47 \pm 0.1$ & $0.46 \pm 0.1$ & $0.48 \pm 0.1$ \\
\hline
\end{tabular}

$\star$ * $\mathrm{p}<0.05$

The calculated average Z-scores and Percentile scores of weight, height and BMI in Bulgarian girls and boys were within the norm, according to the international standards of the World Health Organisation (WHO, 2007). The average Z-scores and Percentile scores of weight and BMI in English boys, as well as the Z-scores of weight in English girls, were shown to be slightly above the norm for their gender and age. The other scores for English children were within the WHO norms. The average waistto-height ratio (WHtR) in all groups was below the global cut-off value of 0.5 (health risk of obesity). The individual results revealed that 17 children had a BMI Z-score greater than $+1 \mathrm{SD}$ (overweight) and 16 had a BMI Z-score greater than $+2 \mathrm{SD}$ (obese) according to the WHO norms. These children included individuals from each group, and none of the four groups was shown to have a significantly higher level of overweight or obese pupils, because the number of cases was insufficient in order to be able to draw this conclusion. The WHtR of 27 children (20 of whom were assessed as overweight or obese according to their BMI Z-score) was above the global cut-off point where obesity is deemed to pose a health risk. Only four individuals had a BMI Z-score less than -1SD (1st grade thinness), and there were no cases of very low BMI Z-score (2nd grade thinness $<-2 \mathrm{SD}$ and 3rd grade thinness $<-3 \mathrm{SD}$ ).

The results of the modified PAQ-C test of the Bulgarian and English children are presented in Table 2. Significant differences between the groups were recorded in four out of the eight questions which comprise the modified PAQ-C. Bulgarian boys and girls showed significantly higher levels of physical activity during physical education classes (Q2), and lower physical activity during break-time, lunchtime and after-school activities (Q3, Q4 and Q5) in comparison with English children.

Table 2. Descriptive characteristics of the modified PAQ-C of all the 81 participants who met the verification criteria (Mean \pm SD)

\begin{tabular}{|l|l|l|l|l|}
\hline & \multicolumn{1}{|c|}{$\begin{array}{c}\text { Bulgarian Females } \\
(\mathrm{n}=27)\end{array}$} & \multicolumn{1}{|c|}{$\begin{array}{c}\text { BulgarianMales } \\
(\mathrm{n}=31)\end{array}$} & $\begin{array}{c}\text { English Females } \\
(\mathrm{n}=8)\end{array}$ & $\begin{array}{c}\text { English Males } \\
(\mathrm{n}=15)\end{array}$ \\
\hline Q1. Spare-time activity: sports & $2.0 \pm 0.6$ & $2.1 \pm 0.2$ & $1.9 \pm 0.7$ & $2.2 \pm 0.5$ \\
\hline $\begin{array}{l}\text { Q2. Activity during physical edu- } \\
\text { cation classes }\end{array}$ & $4.8 \pm 0.5 \mathrm{c}, \mathrm{D}$ & $5.0 \pm 0.0 \mathrm{C}, \mathrm{D}$ & $4.0 \pm 0.8$ & $4.1 \pm 0.9$ \\
\hline Q3. Break-time activity & $2.2 \pm 0.7 \mathrm{C}, \mathrm{D}$ & $2.8 \pm 0.9 \mathrm{C}, \mathrm{D}$ & $4.3 \pm 1.0$ & $4.7 \pm 0.6$ \\
\hline Q4. Lunch-time activity & $2.6 \pm 0.7 \mathrm{C}, \mathrm{D}$ & $2.7 \pm 0.9 \mathrm{C}, \mathrm{D}$ & $4.3 \pm 1.0$ & $4.3 \pm 1.2$ \\
\hline Q5. After-school activity & $1.0 \pm 0.0 \mathrm{C}, \mathrm{D}$ & $1.0 \pm 0.0 \mathrm{C}, \mathrm{D}$ & $3.1 \pm 1.4$ & $3.0 \pm 1.4$ \\
\hline Q6. Evening activity & $3.1 \pm 0.7$ & $3.3 \pm 0.7$ & $2.6 \pm 1.3$ & $2.6 \pm 1.1$ \\
\hline Q7. Weekend-activity & $2.9 \pm 0.6$ & $3.1 \pm 0.6$ & $3.1 \pm 1.4$ & $3.4 \pm 0.9$ \\
\hline Q8. Activity frequency & $2.6 \pm 0.8$ & $3.2 \pm 0.9$ & $2.1 \pm 1.0$ & $3.0 \pm 1.4$ \\
\hline Total PAQ-C activity & $2.66 \pm 0.26^{\mathrm{c}}, \mathrm{D}$ & $2.90 \pm 0.28 \mathrm{~d}$ & $3.17 \pm 0.67$ & $3.41 \pm 0.62$ \\
\hline
\end{tabular}

$\mathrm{p}<0.001$ vs. Bulgarian Females (A); vs. Bulgarian Males (B); vs. English Females (C); vs. English Males (D)

$\mathrm{p}<0.01$ vs. English Females (c); vs. English Males (d)

$\mathrm{p}<0.05$ vs. English Females (c) 
The average total PAQ-C score for all four groups was shown to be within the range of medium physical activity for children (PAQ-C score $>2.50$ and $<$ 3.50). Statistically significant differences in the total PAQ-C scores were observed between the Bulgarian and English girls ( $2.66 \pm 0.26$ vs. $3.17 \pm 0.67$, respectively, $\mathrm{p}<0.05)$, the Bulgarian and English boys $(2.90$ \pm 0.28 vs. $3.41 \pm 0.62$, respectively, $\mathrm{p}<0.01$ ), and between the Bulgarian girls and the English boys $(2.66 \pm 0.26$ vs. $3.41 \pm 0.62$, respectively, $\mathrm{p}<0.001)$. In addition, eta-squared $\left(\eta^{2}\right)$ measure of effect size employed in ANOVA was also calculated and shown to be 0.319 , which indicated large effects, according to the benchmarks provided by Cohen (Cohen, 1988).

There was no significant difference between children with a BMI Z-score greater than +1 SD (overweight and obese, $n=33$ ) and children with a BMI Z-score within the norm in terms of the total PAQ-C score.

\section{Discussion}

The average total PAQ-C scores for English boys and girls were above the cut-off level (2.9 and 2.7, respectively), which categorises them into either "sufficiently active" or "low-active", according to normative PAQ scores for English children and adolescents (Voss et al., 2013). Further research need to be carried out in order to obtain normative PAQ scores for Bulgarian children and adolescents.

Bulgarian children showed significantly lower scores in Q3, Q4 and Q5 (break-time, lunch-time and after-school activities) in comparison with English children. These differences probably occurred due to the variety of before-school and after-school activities added to the English curriculum.

In this study, we recorded 17 overweight (BMI Z-score $>+1 \mathrm{SD}$ ) and 16 obese children (BMI Z-score $>+2 \mathrm{SD}$ ), which made a total of 33 pupils ( $41 \%$ of all participants) at risk as far as health is concerned. The waist-to-height ratio (WHtR) assessment showed that 27 out of 81 children ( $33 \%$ of all participants) were at risk according to the global cut-off value of 0.5 (Ashwell and Hsieh, 2005). The findings of our study are in accordance with other authors who observed overweight/obesity frequency in children to range from $30 \%$ to $45 \%$ (Guinhouya et al., 2009, Sanchez-Vaznaugh et al., 2015). WHtR provided a good alternative assessment to the BMI, which was also found in other studies (McCarthy and Ashwell, 2006, Brown et al., 2017) Moreover, WHtR is seen to be an effective and simple screening index of body composition during growth, both because it predicts cardiovascular disease risk factors better than BMI (Savva et al., 2000, Hara et al., 2002, Kahn et al., 2005), and because it is only loosely correlated to age, so there is no need for age- and gender-specific values in its assessment (Taylor et al., 2011).

The overweight and obese children (BMI Z-score $>+1 S D, n=33$ ) and those within the norm (BMI Z-score $<+1 S D$ and $>-1 S D$ ) had almost identical physical activity levels, as assessed by the total PAQ-C score $(2.98 \pm 0.48$ and $2.92 \pm 0.50$, respectively), which was also observed in obese and normal weight girls (Rourke et al., 2003). Similar findings of the total PAQ-C score were recorded in a study of 83 obese children, who were divided into groups of high health risk and low health risk (3.00 \pm 0.66 and $3.01 \pm 0.65$, respectively) (Ball et al., 2003).

In addition, we compared the physical activity levels of children at risk due to obesity according to the $\mathrm{WHtR}$ classification $(n=27)$ and those within the norms (WHtR $<0.5, n=54)$. In the same way, there was no significant difference in the total PAQ-C score between children experiencing a health risk owing to obesity and the rest ( $2.83 \pm 0.37$ vs $2.99 \pm 0.52$, respectively).

Physical inactivity has been defined by the WHO as one of the leading risk factors in terms of global mortality (6\% of deaths worldwide), along with blood pressure (13\%), tobacco use (9\%), high blood glucose (6\%), and overweight and obesity (5\%) (WHO, 2009). Children and young people should be physically active on a daily basis, with play, games, sports, transportation, recreation, physical education, or planned exercises being part of their everyday activities (WHO, 2010), and we believe it to be of particular importance to improve the methods for assessing PA and to implement them as part of regular monitoring in schools.

\section{References}

AMERICAN_COLLEGE_OF_SPORTS_MEDICINE2014. ACSM's Health-Related Physical Fitness Assessment Manual, Fourth Edition, USA, Lippincott Williams and Wilkins.

ASHWELL, M. \& HSIEH, S. D. 2005. Six reasons why the waist-to-height ratio is a rapid and effective global indicator for health risks of obesity and how its use could simplify the international public health message on obesity. Int J Food Sci Nutr, 56, 303-7.

BALL, G., MARSHALL, D. \& MCCARGAR, L. 2003. Fatness and Fitness in Obese Children at Low and High Health Risk. Pediatric Exercise Science, 15, 392-405. 
BERVOETS, L., VAN NOTEN, C., VAN ROOSBROECK, S., HANSEN, D., VAN HOORENBEECK, K., VERHEYEN, E., VAN HAL, G. \& VANKERCKHOVEN, V. 2014. Reliability and Validity of the Dutch Physical Activity Questionnaires for Children (PAQ-C) and Adolescents (PAQ-A). Arch Public Health, 72, 47.

BIDDLE, S. J., GORELY, T., PEARSON, N. \& BULL, F. C. 2011. An assessment of self-reported physical activity instruments in young people for population surveillance: Project ALPHA. Int J Behav Nutr Phys Act, 8, 1.

BRENER, N. D., COLLINS, J. L., KANN, L., WARREN, C. W. \& WILLIAMS, B. I. 1995. Reliability of the Youth Risk Behavior Survey Questionnaire. Am J Epidemiol, 141, 575-80.

BROWN, E. C., KILGORE, J. L., BUCHAN, D. S. \& BAKER, J. S. 2017. A criterion-referenced assessment is needed for measuring child obesity. Res Sports Med, 25, 108-110. COHEN, J. 1988. Statistical Power Analysis for the Behavioral Sciences, USA, Lawrence Erlbaum Associates. CROCKER, P. R., BAILEY, D. A., FAULKNER, R. A., KOWALSKI, K. C. \& MCGRATH, R. 1997. Measuring general levels of physical activity: preliminary evidence for the Physical Activity Questionnaire for Older Children. Med Sci Sports Exerc, 29, 1344-9.

ELLIOT, E., ERWIN, H., HALL, T. \& HEIDORN, B. 2013. Comprehensive School Physical Activity Programs: Helping All Students Achieve 60 Minutes of Physical Activity Each Day [Position statement]. American Alliance for Health, Physical Education, Recreation and Dance.

GANLEY, K. J., PATERNO, M. V., MILES, C., STOUT, J., BRAWNER, L., GIROLAMI, G. \& WARREN, M. 2011. Health-related fitness in children and adolescents. Pediatr Phys Ther, 23, 208-20.

GUINHOUYA, C. B., APETE, G. K. \& HUBERT, H. 2009. Diagnostic quality of Actigraph-based physical activity cut-offs for children: what overweight/obesity references can tell? Pediatr Int, 51, 568-73.

HAGSTROMER, M. \& SJOSTROM, M. 2010. Standard operating procedure for the use of accelerometry in monitoring of physical activity at population level. $A L$ PHA Assessing Levels of Physical Activity.

HARA, M., SAITOU, E., IWATA, F., OKADA, T. \& HARADA, K. 2002. Waist-to-height ratio is the best predictor of cardiovascular disease risk factors in Japanese schoolchildren. J Atheroscler Thromb, 9, 127-32.

KAHN, H. S., IMPERATORE, G. \& CHENG, Y. J. 2005. A population-based comparison of BMI percentiles and waist-to-height ratio for identifying cardiovascular risk in youth. J Pediatr, 146, 482-8.

KOWALSKI, K., CROCKER, P. \& DONEN, R. 2004 The Physical Activity Questionnaire for Older Children (PAQ-C) and Adolescents (PAQ-A) Manual. Canada: College of Kinesiology, University of Saskatchewan.

KOWALSKI, K. C., CROCKER, P. R. E. \& FAULKNER, R. A. 1997. Validation of the Physical Activity Questionnaire for Older Children. Pediatric Exercise Science, 9, 174-186. LAKENS, D. 2013. Calculating and reporting effect sizes to facilitate cumulative science: a practical primer for t-tests and ANOVAs. Front Psychol, 4, 863.

MCCARTHY, H. D. \& ASHWELL, M. 2006. A study of central fatness using waist-to-height ratios in UK children and adolescents over two decades supports the simple message-'keep your waist circumference to less than half your height'. Int J Obes (Lond), 30, 988-92.

ROURKE, K. M., BREHM, B. J., CASSELL, C. \& SETHURAMAN, G. 2003. Effect of weight change on bone mass in female adolescents. J Am Diet Assoc, 103, 369-72.

SANCHEZ-VAZNAUGH, E. V., SANCHEZ, B. N., CRAWFORD, P. B. \& EGERTER, S. 2015. Association between competitive food and beverage policies in elementary schools and childhood overweight/obesity trends: differences by neighborhood socioeconomic resources. JAMA Pediatr, 169, e150781.

SAVVA, S. C., TORNARITIS, M., SAVVA, M. E., KOURIDES, Y., PANAGI, A., SILIKIOTOU, N., GEORGIOU, C. \& KAFATOS, A. 2000. Waist circumference and waist-to-height ratio are better predictors of cardiovascular disease risk factors in children than body mass index. Int J Obes Relat Metab Disord, 24, 1453-8.

STK-SPORT. 2017a. Modified Physical Activity Questionnaire (PAQ-C) [Online]. Available: https://www.stksport.co.uk/images/sports-science-research-icass-2017modified-paq-c.pdf.

STK-SPORT. 2017b. Modified Physical Activity Questionnaire (PAQ-C) in Bulgarian language [Online]. Available: https://www.stk-sport.co.uk/images/sports-science-research-icass-2017-modified-paq-c-bg.pdf.

TAYLOR, R. W., WILLIAMS, S. M., GRANT, A. M., TAYLOR, B. J. \& GOULDING, A. 2011. Predictive ability of waist-to-height in relation to adiposity in children is not improved with age and sex-specific values. Obesity (Silver Spring), 19, 1062-8.

U.S._DEPARTMENT_OF_HEALTH_AND_HUMAN_ SERVICES1996. Physical Activity and Health: A Report of the Surgeon General. Atlanta, GA: U.S. Department of Health and Human Services, Centers for Disease Control and Prevention, National Center for Chronic Disease Prevention and Health Promotion. USA.

VOSS, C., OGUNLEYE, A. A. \& SANDERCOCK, G. R. 2013. Physical Activity Questionnaire for children and adolescents: English norms and cut-off points. Pediatr Int, 55, 498-507.

WANG, J. J., BARANOWSKI, T., LAU, W. P., CHEN, T. A. \& PITKETHLY, A. J. 2016. Validation of the Physical Activity Questionnaire for Older Children (PAQ-C) among Chinese Children. Biomed Environ Sci, 29, 177-86.

WHO. 2007. BMI-for-age (5-19 years) [Online]. World Health Organization. Available: http://www.who.int/ growthref/who2007 bmi for age/en/ [Accessed accessed on 20 September 2017].

WHO 2009. Global health risks: mortality and burden of disease attributable to selected major risks. Geneva: World Health Organization.

WHO 2010. World Health Organizoation - Global recommendations on physical activity for health. Geneva:. WHO Publications.

Contact information with the corresponding author:

Stefan Kolimechkov, PhD student at the NSA 'Vassil Levski', Sofia, Bulgaria, mobile:+44799957870034, Chalfont Road N99LW, London, UK, kolimechkov@gmail.com 